This is an electronic reprint of the original article. This reprint may differ from the original in pagination and typographic detail.

Please cite the original version: Kallström, A. ; Al-Abdulla, O. ; Parkki , J. ; Häkkinen, M. ; Juusola, H. \& Kauhanen, J. (2021) I had to leave. I had to leave my clinic, my city, leave everything behind in Syria. Qualitative research of Syrian healthcare workers migrating from the war-torn country. BMJ Open 2021;11:, e049941.

doi: 10.1136/bmjopen-2021-049941

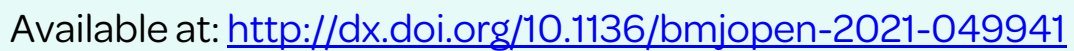




\title{
BMJ Open I had to leave. I had to leave my clinic, my city, leave everything behind in Syria. Qualitative research of Syrian healthcare workers migrating from the war-torn country
}

\author{
Agneta Kallström (D) , ${ }^{1}$ Orwa Al-Abdulla, ${ }^{1}$ Jan Parkki, ${ }^{2}$ Mikko Häkkinen, ${ }^{3}$ \\ Hannu Juusola, ${ }^{4}$ Jussi Kauhanen ${ }^{1}$
}

To cite: Kallström A, AlAbdulla 0, Parkki J, et al. I had to leave. I had to leave my clinic, my city, leave everything behind in Syria. Qualitative research of Syrian healthcare workers migrating from the war-torn country. BMJ Open 2021;11:e049941. doi:10.1136/ bmjopen-2021-049941

- Prepublication history for this paper is available online. To view these files, please visit the journal online (http://dx.doi. org/10.1136/bmjopen-2021049941).

Received 26 February 2021 Accepted 08 0ctober 2021

Check for updates

(c) Author(s) (or their employer(s)) 2021. Re-use permitted under CC BY-NC. No commercial re-use. See rights and permissions. Published by BMJ.

${ }^{1}$ Faculty of Health Sciences, Institute of Public Health and Clinical Nutrition, University of Eastern Finland, Kuopio, Finland ${ }^{2}$ Helsinki, Finland

${ }^{3}$ Laurea University of Applied Sciences, Vantaa, Finland

${ }^{4}$ Department of Cultures, University of Helsinki, Helsinki, Finland

Correspondence to Mrs Agneta Kallström; agneta.kallstrom@helsinki.fi

\section{ABSTRACT}

Objectives To explore the reasons why healthcare workers migrate from Syria, a country where conflict has been raging for over a decade.

Design A qualitative study was performed using semistructured interviews. Semistructured questions guided in-depth interviews. Content analysis was used. Setting Participants were Syrian healthcare workers who had worked in the country after the conflict started in 2011, but at some point left Syria and settled abroad. The interviews took place in Turkey and Europe in 2016 and 2017.

Participants We collected data from 20 participants (18 males and 2 females) through snowball sampling method. Results Healthcare workers migrated from Syria only because of security reasons. In most cases, the decision to leave resulted from the generalised violence against civilians by different warring parties, mainly the Government of Syria and the Islamic State. Intentional attacks against healthcare workers were also one of the main reasons for leaving. Some participants had a specific notable trigger event before leaving, such as colleagues being detained or killed. Many participants simply grew tired of living under constant fear, with their families also at risk.

Conclusions This research adds to the body of literature on violence against healthcare workers in Syria. It helps to understand the reasons why healthcare workers leave the country. The study also indicates that the international community has failed to protect Syrian healthcare workers. The intensity of the conflict has left many healthcare workers with no other option than to leave. Understanding this migration will enable the discovery of new solutions for protecting healthcare workers in current and future conflicts.

\section{INTRODUCTION}

Armed conflicts challenge normal healthcare provision. Healthcare workers (HCWs), one of the most crucial factors of healthcare services, often migrate away from conflictaffected areas. ${ }^{1-3}$ In 2020, at least 162 HCWs
Strengths and limitations of this study

- This qualitative, semistructured interview study, employing snowball sampling method, explored the reasons behind high numbers of Syrian healthcare workers' migration.

- Previous empirical research, especially qualitative explorations of the migration of Syrian healthcare workers, is almost non-existent.

- A multidisciplinary research team conducted the interviews, including experienced local front-line healthcare workers, allowing unique access to sensitive information.

- Although the interviews were conducted with a relatively small sample of participants, the saturation point for the data was reached.

- Most of the participants were male physicians with a specialty, were born in Aleppo governorate and resided in Turkey during the study.

in 20 countries were killed and 152 injured. ${ }^{4}$ Notably, attacks against HCWs took place during the events known as the Arab Spring, a revolutionary wave of demonstrations and protests starting in 2010 from Tunisia. Antigovernment demonstrations escalated into violence in several states around the Middle East. In Syria, the events turned into an armed conflict that is still ongoing. Especially in Syria, Bahrain, Yemen and Iraq, HCWs have been targeted since the Arab Spring. ${ }^{5-7}$

During the decade of war, hospital bombings have become a trademark in the Syrian conflict. Violence against HCWs and thus the denial of healthcare services to the population has been used as a war strategy ${ }^{7}$ even though the International Humanitarian Law (IHL) stipulates that the healthcare system is protected in a time of war. The government must protect HCWs' medical neutrality, 
which means freedom for the HCWs to take care of patients regardless of their political affiliations. ${ }^{8}$ From the beginning of the conflict, the Government of Syria (GoS) is reported to have punished HCWs for treating injured protestors ${ }^{9}{ }^{10}$ regardless of the IHL statute that under no circumstances shall any person be punished for carrying out medical activities compatible with medical ethics, regardless of the person benefiting from them. ${ }^{11}$ In 2012, the GoS effectively criminalised healthcare provision to people belonging to the opposition. ${ }^{10} 12$

At least 930 HCWs have been killed in Syria from 2011 through March 2021. All warring parties have attacked HCWs; however, the GoS with Russia has been held responsible for this $91 \%$. Non-state armed groups (NSAGs), Islamic State in Iraq and Syria (ISIS) and Kurdish or unidentified forces are responsible for $9 \%$. The primary cause of death $(55 \%)$ is aerial or ground bombardment. HCWs have also died when detained and tortured or just executed. ${ }^{13-16}$ More than $70 \%$ of qualified HCWs have left the country. In some areas, specific specialties are absent. ${ }^{17}{ }^{18}$ Further, medical students have had to leave their basic and specialisation studies. ${ }^{19}$ The absence of professionals will add to the challenges of both current and future treatment of the population.

HCWs, especially physicians, tend to migrate at the early stage of the conflict because they have the resources to leave. ${ }^{20}$ The financial issues, desire for further education and a better lifestyle are some key reasons for migration. ${ }^{21}$ Further, generalised insecurity, targeted violence and the desire to protect one's family are also known reasons. ${ }^{22} 23$ In Iraq, a country that has experienced perpetual violence for decades, male physicians over 30 years of age face a significantly increased risk of being kidnapped or assassinated. ${ }^{124}$

In the study by Doocy et $a l,{ }^{25}$ leaving Iraq was associated with a violent event for nearly $61 \%$ of HCWs. Of the physicians who left the country, $75 \%$ had experienced violence against their household members before reaching the decision to leave. In another study by Al-Khalisi,${ }^{26} 60 \%$ of participants had left Iraq for security reasons. However, factors demoralising the HCWs are complex, and the decision to leave is made based on multiple reasons. ${ }^{124}$

Although research on violence against HCWs has increased in recent years, the number of studies is still limited. Violence in Iraq has been studied somewhat more extensively than that of other conflict-afflicted countries. However, the violence against HCWs in Iraq differs from that in Syria, with almost no airstrikes against healthcare facilities. In Syria, Fouad $e t a l^{7}$ have argued that the bombing of hospitals is part of the weaponisation of healthcare, a strategy of war, by the GoS.

Most analyses of violence against the healthcare system in Syria have focused on damage to healthcare infrastructures, such as hospitals and ambulances. ${ }^{27-29}$ Few studies have explored HCWs' personal experiences through the conflicts, ${ }^{1730}$ and none of them examine the reasons for professionals leaving Syria. Furthermore, existing reviews do not consider how violence by different warring parties, such as arrests, detention and kidnappings, affects the decision to leave. There are significant missing data on secondary trauma, such as witnessing killings of civilians and colleagues and how the constant fear of the conflict itself affects the outward mobility of healthcare professionals.

Initially, we aimed to study HCWs' experiences of violence in the ongoing conflict. From that data, a repeating pattern behind migration emerged organically. Consequently, this study focuses on the reasons why HCWs leave Syria. Such loss of resources in a crisis setting is detrimental to the functioning of healthcare and public health. Understanding this behaviour is highly beneficial in order to limit its effects.

\section{METHODS}

\section{Study design and sampling}

The participants were identified using a snowball sampling method (SSM). They had to represent the category of HCWs according to the International Labour Organization's International Standard Classification of Occupations- $08 .^{31} \mathrm{SSM}$ was chosen to increase trust in the research, given the sensitivity of the topic. ${ }^{32}$ The first participant in the chain was a Syrian healthcare professional living in Gaziantep, Turkey. He had contacted the University of Eastern Finland earlier and was asked to participate (as he was well suited for this study). One female (AK) and two male (MH, OA-A) researchers conducted the interviews in English or Arabic. The participants selected a suitable place for the interviews, and only the researchers and the participants were present at the time. Participants were informed of the researchers' previous research and backgrounds. They were also given a written handout with relevant study description and contact information. They were given information about the aim and goals of the study. In practice, the interviews started with background questions and then moved onto the semistructured main part. After the interview was concluded, the participants were asked to name a few other potential candidates interested in participating in the research. Volunteers among them contacted our research team.

The duration of the interviews varied from 45 to $90 \mathrm{~min}$. We terminated interviews when further inquiry provided no significant new themes.

\section{Measurement and analysis}

A semistructured in-depth interview guided the discussion with the participants. The study was focused on HCWs' reasons for migration from the country after 2011. This approach was based on a constant dialogue between the researcher and the interviewee. While there was a common base list of structured questions to guide the general direction of the interview, open-ended elaboration was encouraged. Additional personalised questions were asked ad hoc to explore any further relevant themes each interviewee knew and was willing to talk 
about. Such flexible technique enabled the interviewer to explore the values and feelings of the participants more thoroughly than any strictly structured interview format would allow. ${ }^{33}$

We defined violence as 'the intentional use of physical force or power, threatened or actual, against oneself, another person, or against a group or community, that either results in or has a high likelihood of resulting in injury, death, psychological harm, maldevelopment or deprivation' ${ }^{34}$ The attacks against HCWs were understood here as any act of verbal or physical violence or obstruction or threat of violence that interferes with the availability, access, and delivery of curative and/or preventive health services during emergencies. ${ }^{35}$

After the interviews were transcribed verbatim and triangulated with handwritten notes, the transcripts were examined. In order to identify the relevant themes, we used inductive content data analysis. The most significant repeating theme in the overall data turned out to be an emphasis on migration, that is, the reasons why the HCWs left the country. Answers were coded into categories using the Excel program. The classifications were based on experiences that indicated motivational factors for leaving the country. These factors were sought both from the direct answers to structured questions and from the free form replies. These were then classified into thematically unified subgroups. No previously set system for such division was used, but the classification emerged organically from the population of factors introduced by the interviewees.

Quotations have been used to illustrate the themes and findings and provide an authentic voice to the participants.

\section{Ethical approval}

The interviews were recorded with the permission of the participants, and consent was obtained verbally. Anonymity and confidentiality were ensured. Participants had an opportunity to ask questions concerning the study. Participants were informed that they could interrupt or abandon the interview if wanted.

The principles in the Declaration of Helsinki were observed in all stages of the study.

\section{Patient and public involvement}

No patients or members of the general public were involved in the conduct of this research.

\section{RESULTS}

\section{Study population}

The qualitative study is based on semistructured interviews $(n=20)$ of Syrian HCWs who have left the country since 2011. Interviews $(n=17)$ were conducted in Gaziantep, a Turkish municipality adjacent to the Syrian border where participants resided at the time of interviews in June to July 2016 and early 2017. Additional interviews $(n=3)$ were conducted in Europe from late 2016 to early 2017. Altogether, participants consisted of 18 males and 2 females.
Table 1 Interviewees' demographic information

\begin{tabular}{|c|c|}
\hline Interviews & 20 \\
\hline \multicolumn{2}{|l|}{ Gender } \\
\hline Male & 18 \\
\hline Female & 2 \\
\hline Age range & $26-47$ years \\
\hline Mean age & 36 years \\
\hline \multicolumn{2}{|l|}{ Place of birth (governorate) } \\
\hline Aleppo & 12 \\
\hline Deir Ez-Zour & 2 \\
\hline Raqqa & 2 \\
\hline Hama & 1 \\
\hline Homs & 1 \\
\hline Idlib & 1 \\
\hline Abroad & 1 \\
\hline \multicolumn{2}{|l|}{ Family status } \\
\hline Married & 16 \\
\hline Children & 14 \\
\hline \multicolumn{2}{|l|}{ Professions } \\
\hline Physicians, total & 14 \\
\hline Physician with specialty & 9 \\
\hline General practitioner & 5 \\
\hline Pharmacist & 3 \\
\hline Nurse & 1 \\
\hline Dentist & 1 \\
\hline Healthcare manager & 1 \\
\hline
\end{tabular}

The age of participants ranged from 26 to 47 years. The mean age was 36 years. Most of the participants were born in the Aleppo governorate $(n=12)$. The other participants represented a variety of other Syrian provinces. Most of the participants were married $(\mathrm{n}=16)$ and had at least one child $(\mathrm{n}=14)$ (table 1$)$.

The majority of people interviewed $(n=14)$ were physicians with postgraduate specialty; surgery and paediatrics were most common $(n=9)$. Other healthcare professionals, such as nurse (1), pharmacists (3), health service manager (1) and dentist (1), were also interviewed. All those interviewed had worked in Syria during the conflict at some point. The working experience varied from almost none to over 20 years.

One of the participants was a medical student and few general practitioners were residents in specialty training. They all had to suspend their studies because of the ongoing violence and leave Syria.

All reasons for leaving Syria were related to violence that started after the demonstrations against the regime in 2011. The HCWs suffered either from general strain under the violent environment, or were targeted by several specific violations or both. All participants expressed that their profession was the reason for targeting. The 
relative impact of these different forms of insults is further discussed in the study's conclusions.

The participants gradually migrated during the conflict. Some left early when the violence started in 2011-2012, while others left later as the war escalated. Some of them moved to opposition-controlled Eastern Aleppo, some other moved directly to Turkey. Many of those who initially remained in Eastern Aleppo followed. Some migrated to Lebanon due to geographical reasons. Once outside Syria, some HCWs continued to Europe to seek asylum.

\section{Generalised violence}

When demonstrations escalated and violence spread after 2011, the participants considered this as one of the turning points in their life. They described their experiences and feelings about what they had witnessed. They had seen atrocities against civilians, including their family and friends. People had been arbitrarily arrested and others randomly disappeared.

My friends were arrested in front of me. They were beaten, tortured in the streets. I saw these incidents. Everyone in Syria saw this. [The GoS was] killing people and shooting. Using tear gas, live bullets. (General practitioner, male)

Before the territorial division between different warring factions, especially the parting of NSAG-controlled Eastern and GoS-controlled Western side of Aleppo, the participants had regularly commuted through GoS checkpoints. They described that the atmosphere had become oppressive. Constant check-ups, arbitrary decisions, such as detainment by the GoS, and increased violence caused widespread psychological stress among the participants.

This fear of daily violence caused stress and anxious feelings. I could not sleep. I was very afraid. I decided to stop working. The reason for this was that I was stopped and bullied at the military checkpoint. I was asked ID card. All kinds of questions: 'what you are doing in this city that is not your hometown, and where does your family live'. They just wanted to bully me. Fear of being detained was the reason I left Syria. (Pharmacist, female)

A participant said that the situation became impossible for GoS to control, and this resulting power vacuum gave NSAGs room to operate. Some participants expressed their mistrust of these organisations and could not expect any help from the dwindling GoS force.

As the conflict evolved, participants witnessed barrel bombs, chemical attacks and airstrikes against civilians.

I saw more than fifteen burnt Kurds, not far from the health care [centre]. Russian airstrike. Their relatives came. They didn't [recognised them] because the bodies were burned. Disgusting. (Specialty doctor, male)
Other warring parties, mainly ISIS and NSAGs, conducted acts of violence against civilians, according to participants. While GoS was considered the main perpetrator, ISIS and other NSAGs, such as Free Syrian Army (FSA) and Jabhat al-Nusra, threatened, mistreated, abducted and killed people as participants described.

FSA took one nurse, tortured him for fivehours. Then he died. Just because his name was the same as some else's. (Specialty doctor, male)

ISIS inspired both fear and animosity against its ideology and values in the participants. The participants shared unnerving anecdotes of the organisation that were circulating and creating an oppressive atmosphere of insecurity. Participants described their friends having severe problems with the organisation. Some of the participants decided to go to Turkey when they noticed ISIS advancing toward the city of Kobane, Aleppo governorate in northern east Syria. They believed fleeing from the organisation was their only option.

One of my friends was kidnapped. The siege became more intensive. I knew that something is going to happen. When Kobane was besieged [by ISIS], I left for Turkey. I had to. (Nurse, male)

Some participants did not indicate a single reason for leaving but instead said they succumbed to the constant stress, fear and harassment because of the escalating situation.

\section{Violence related to personal issues}

While participants were concerned about the generalised violence, their own and their families' safety played an important role in the decision to leave Syria. When violence spread, many participants wanted to take their families to Turkey for safety. Many noted that they wanted to keep their children safe, and in Syria, it was impossible.

I cannot live with my children under these circumstances. I saw what happened in Homs. I saw what happened in Deraa...using guns and aeroplanes... I felt this will happen in my area. This happened for 2-3 days [after leaving] my home. (Health service manager, male)

Participants were told that if a family member was arrested, the entire family would be investigated, and any suspected antigovernment views or actions could lead to family-wide punishments.

After the second time detention [by GoS] my family said: 'Leave the country now'. I left. My family was afraid that I will go to jail again. Four days after I had left, they took my brother and told him, 'Tell your brother that if we catch him'... (Specialty doctor, male)

In many cases, the participant was the breadwinner of the family. Therefore, they were concerned about the financial well-being of their family, should they die. One 
participant mentioned that he would most likely live and work in Syria without a wife and children.

My family is dependent on me. Their existence is depending on me and my survival. I don't want to cause them danger or die as a martyr, and they lost me. It would be my family that would pay the high price. (Specialty doctor, male)

Some male participants expressed the fear of being conscripted in the Syrian forces. Many participants had witnessed atrocities performed by the GoS, and some had even been detained and tortured. They wanted to avoid becoming part of the military forces, and the only option was to leave.

We had to go. I knew that they [the GoS] were after me. I had to leave my studies and leave. I should have gone to the army. That's why the regime was after me. (Specialty doctor, male)

Becoming remarked by ISIS for expressing opposing sentiments or oppressing them in any way was highly dangerous, as many participants noted. Those participants who had fallen in disfavour of the organisation had little option. They had to leave because of the risk of being arrested or even executed.

We talked about ISIS that they are not from Syria and we are not accepting their presence here etc. Later, my friends told me that ISIS is observing my home. I moved to another area. After this incident, one of them [friends] was arrested by ISIS. (Specialist doctor, male)

Although the participants were not explicitly asked for their ethnic background because of the sensitivity, several of them mentioned their Kurdish roots, the minority in Syria. The Kurdish participants felt that they were targeted explicitly by radical Sunni Muslim NSAGs because of their background.

\section{Violence related to being an HCW}

Most of the participants had personally experienced violence that they considered to be connected with their profession. All thought that their profession made them a target. Participants described their experiences since 2011 in detail. The violence included verbal assaults, beatings, detainment and torture. They had been shot at or been in an ambulance when assaulted. Some participants described the situation when they had been in a healthcare facility at the time of the aerial bombardments by GoS and later by Russia.

This [name retracted] hospital was targeted by a Russian airstrike. One of my friends died in this airstrike, the doctor [name retracted]. I'm very sad about him. (Specialty doctor, male)

All participants described the violence that their colleagues had experienced, and those were similar to their own. Some colleagues and coworkers were arrested, had gone missing and were never seen again. Some were later found dead with marks of severe abuse. Participants had also lost their colleagues in airstrikes.

I have seen colleagues killed in front of my eyes. In [place retracted] was a doctor, and she was taken. They [the unknown perpetrator] took her. Later she was found raped and dead. (Specialty doctor, male)

Participants saw and experienced their colleagues being humiliated and occasionally arrested in the hospitals, sometimes in the middle of medical operations.

[Name retracted] was like a brother. He got arrested in a real, humiliating way. He was changing the bandages to the patient. They [GoS] took him from the room. [They] covered his face in front of the staff of the hospital. They didn't let anyone talk to him or ask where $[\mathrm{GoS}]$ were taking him. (Specialty doctor, male)

Some participants decided to leave once their colleagues had been arrested, gone missing or found dead. The fear of being caught by the GoS was a significant reason to escape. In addition, many participants were afraid that their captured colleagues were giving up their name under torture. However, a relationship marked by solidarity existed among the professionals.

One of my colleagues was arrested. Under a lot of pressure, they have the methods that you talk. He mentioned my name. I had to pay to get out of Syria and out of Aleppo. I left everything behind. (General practitioner, male)

Additionally, as HCWs, participants were concerned about the roadblocks. Crossing them was considered stressful when travelling for work. Participants described the incidents on the checkpoints. Sometimes they were stopped for extended periods and inspections, sometimes detained. Participants considered that this was due to their profession.

At the $[\mathrm{GoS}]$ checkpoints, many doctors were arrested. One orthopaedic and his wife. This doctor had no problems [with GoS], and he had done nothing. He was taken from the roadblock. He was in prison for five months. His wife had to pay 800000 Syrian pounds to get him away. This was in 2013. (General practitioner, male)

Hospitals became threatening due to constant military and GoS presence, according to participants. Armed soldiers were seen as intimidating and reduced the willingness of HCWs to show up at work, as many participants depicted. In addition, one of the participants described having seen sharpshooters on hospital roofs aiming at people and even shooting them.

In the hospital where I worked, the situation changed. It started to look like a military base. The soldiers were going in and out with their weapons. 
Most doctors and other healthcare workers did not come to work because they were afraid of the soldiers with guns. They could cause you troubles for no reason. (Specialty doctor, male)

Many participants described that in many cases, when the governmental forces arrived to investigate the hospital, HCWs warned their colleagues in danger of being arrested. The warnings allowed them to avoid capture. However, this was very dangerous, and in several cases, the participants reported that GoS had arrested their colleagues.

I heard that my name was asked in the hospital I am working. I felt that I was in danger. I fled out of the country. When someone is asking about you in Syria, that is the mukhabarat [security service]. My friend was arrested in front of the hospital. One week before his arrest, they start to ask about him. One nurse in the hospital called me and [said] 'There is someone from the military department and asked about you'. (General practitioner, male)

The opposite was also confirmed, as some participants remembered. A fraction of the workers sided with the GoS. They could spy on their colleagues, record their conversations and then turn them in. Due to strict internal monitoring, antigovernment discussions, even in private settings, could be carried to government officials according to participants.

They [security forces] opened the phone, and there were conversations between doctors. Some doctor or nurse have recorded conversations and then give them to the security service. We were arrested for 2428 hours. (Specialty doctor, male)

Some participants said that they were persuaded to abandon their country only after being personally threatened or imprisoned-some for extended periods.

After [released from the prison after six months], another intelligence department [officer] came to my house. They were looking for me. They were asking for my house - again. I left Aleppo for Turkey. (Specialty doctor, male)

A few years after the beginning of the conflict, other warring parties started causing problems for HCWs. The participants considered ISIS as the most significant threat after the GoS.

ISIS arrested me. It was scary in 2014 in Tel Abyad. For seven hours, then they let me leave. This was the main reason I decided to leave Syria. After being interrogated by ISIS, I decided that even I have studied for 12 years, I am not ready for this, getting 1000 to 2000 USD per month [salary]. Those seven hours they interrogated me was a changing moment in my life. It was the first time when something like that happened to me. Those seven hours felt like seven years. (Specialty doctor, male)
HCWs are more likely to encounter events and become victims of mistreatment due to the very nature of their profession. Many participants were forced to witness the abuse of civilians while practising their work. The participants describe having seen people subjected to violence and taken by GoS. Many of those persons imprisoned had been tortured before they were brought to hospitals.

We have seven patients taken by intelligence. We were receiving patients from the intelligence after torturing in prison to cure them. Sometimes they bring dead bodies and throw them in front of us. Sometimes they took patients from the hospitals. Somebody who went to protest was shot or stabbed by Shabbiha [pro-government militia]. He [patient] came with his family or ambulance or himself to the hospital to take treatment. They knew [GoS] that he was there, and they would come. Even before treating him. Or while treating him. I know many cases. (Specialty doctor, male)

\section{DISCUSSION}

To our knowledge, this is the first research to examine the reasons why Syrian HCWs migrate from the conflictaffected country. This qualitative study is based on semistructured interviews of the 20 Syrian HCWs who left the country after 2011. In previous studies in conflict settings, avoiding the violence of war has not been the HCWs' sole reason to leave; financial issues and concerns regarding education were also mentioned as reasons for leaving. ${ }^{212}$ However, we found no HCWs indicating either factor as the primary cause for leaving. Doocy et $a l^{25}$ state that the choice to go is a sum of many different factors. Our study suggested that all reasons to leave Syria were related to security issues. It appears that the ever-present violence and complexity of the war in Syria superseded all other concerns.

HCWs considered their profession to be a reason for the violence they experienced. The GoS seemed to target HCWs specifically because of their profession. This intentional targeting is in accordance with multiple reports and studies. ${ }^{74} 27283036$ The GoS was also responsible for generalised violence and violence related to personal issues. ISIS was primarily accountable for generalised violence and sometimes attacked the participants for their individual actions such as expressing their political opinions.

Many HCWs had to weigh the lack of prospects and accumulating stress against the equally intimidating challenge of actually trying to leave the country. While some participants had a specific notable trigger event, such as a colleague being detained or killed, many just grew tired of living under constant threat and fear.

The average participant in this study was a 36-year-old male doctor with a specialty. He was married and had a family and at least one child. This profile is in accordance with other studies ${ }^{23-25}$ that have shown male gender and 
similar age structure associate with the risk of targeted violence and migration. On the other hand, the need to protect one's family is an important reason to leave. As one of our participants said, he would be working in Syria if he did not have a family. When experienced HCWs leave the country, the remaining personnel are left without sufficient professional expertise, as has happened in Iraq. ${ }^{1}$ This reduces the quality of healthcare services and adds to the workload of those staying. ${ }^{1730}$

The emotional distress of violence on HCWs is enormous, as noted in the study by Hamid et al. ${ }^{37}$ Participants have lost colleagues, friends and family members. In addition to their experienced traumas, they are most likely to have secondary traumas through witnessing atrocities against civilians while working as HCWs near the front line of war. Despite this, some of our participants were visiting Syria every month for humanitarian work. The motivations for this should be studied more closely because it might help find solutions to get senior HCWs back permanently to Syria now, as the violence starts to show signs of decreasing. The availability of healthcare personnel is one of the central issues in rebuilding civil society. However, finding qualified HCWs is challenging when the majority of them have left the country. ${ }^{17}$ Additionally, medical students had to leave their undergraduate studies and postgraduation training to flee the violence. ${ }^{19}$ These amount to a significant loss of human capital for the Syrian healthcare system. Restoring both current and future provisions of services to an acceptable level will be highly demanding.

\section{Strengths and limitations}

The present research is subjected to several limitations. First, while we reached participants from several different Syrian governorates (Homs, Daraa, Deir Ez-Zour, Raqqa, Hama, Rif Damascus), most were originally from Aleppo. On the other hand, they had worked in different locations and had experienced violence in areas under all warring parties. More studies should focus on recruiting participants from all these areas, especially from those that ISIS had controlled. Many interviewees considered ISIS as one of the main factors for leaving. Second, the SSM is conducive to selection bias. ${ }^{32}$ We used three different parallel SSM networks to reduce this. Third, the perspectives of female HCWs are partly missing. Future research should concentrate on sex-based violence and on the experiences of female HCWs and their reasons for leaving Syria.

Obtaining data in a conflict setting, especially firsthand accounts of personal experiences, is challenging. However, one of the authors is a Syrian HCW who has lived and worked mainly in NSAG and Kurdish forcecontrolled areas. His first-hand knowledge made this study more valuable and provided a better understanding of the situation in such regions of Syria that researchers generally have not been able to visit due to severe security risks.

\section{CONCLUSION}

This research explores in detail why HCWs have left conflict-torn Syria. Our study explains that local HCWs had no other alternative but to leave their homes and work to protect themselves and their families. In addition, this study gives a voice to Syrian HCWs who have witnessed horrors of conflict with extensive destruction.

Our interviewees described such acts of violence and attacks against healthcare that may constitute violations against Geneva Conventions. Thus, these actions might be considered war crimes and would then require perpetrators to be held accountable.

A better understanding of this type of forced migration is needed to develop approaches to support HCWs psychologically and practically in a time of war. This study enables creation of actionable protocols of intervention diminishing or prevents similar future events.

\section{Twitter Agneta Kallström @AgnetaKallst}

Acknowledgements We are thankful to all those Syrian healthcare workers who trusted us and shared their experience and memories. We also thank the Foundation of the Finnish Institute in the Middle East for supporting AK and MH's field trip to Turkey. We thank the Alfred Kordelin Foundation for supporting AK.

Contributors $\mathrm{AK}, \mathrm{MH}, \mathrm{HJ}$ and JK designed and conceptualised the study. AK, MH and OA-A coordinated and carried out the data collection. AK and JP coded the data. AK, OA-A and JP analysed and interpreted the data. AK led the manuscript writing with contributions from $\mathrm{OA}-\mathrm{A}, \mathrm{JP}, \mathrm{MH}, \mathrm{HJ}$ and JK. All authors reviewed and accepted the final manuscript. As the director of the project, JK is the guarantor of the content of this paper.

Funding This work was supported by the Foundation of the Finnish Institute in the Middle East. In addition, the Alfred Kordelin Foundation (grant number 200218) supported AK's work.

Disclaimer The Foundation of the Finnish Institute in the Middle East or the Alfred Kordelin Foundation was not involved in any step of this research. The notions and views are those of the authors.

Competing interests None declared.

Patient and public involvement Patients and/or the public were not involved in the design, or conduct, or reporting, or dissemination plans of this research.

Patient consent for publication Not required.

Ethics approval An ethical permit for the study was applied for and obtained from the University of Eastern Finland Committee on Research Ethics in 2016.

Provenance and peer review Not commissioned; externally peer reviewed.

Data availability statement Data are available upon reasonable request.

Open access This is an open access article distributed in accordance with the Creative Commons Attribution Non Commercial (CC BY-NC 4.0) license, which permits others to distribute, remix, adapt, build upon this work non-commercially, and license their derivative works on different terms, provided the original work is properly cited, appropriate credit is given, any changes made indicated, and the use is non-commercial. See: http://creativecommons.org/licenses/by-nc/4.0/.

ORCID iD

Agneta Kallström http://orcid.org/0000-0002-5442-3709

\section{REFERENCES}

1 Burnham G, Malik S, Al-Shibli ASD, et al. Understanding the impact of conflict on health services in Iraq: information from 401 Iraqi refugee doctors in Jordan. Int J Health Plann Manage 2012;27:e51-64.

2 Baker A. Syria's Health Crisis Spirals As Doctors Flee. Time, 2014. Available: https://time.com/3968/syrias-health-crisis-spirals-asdoctors-flee/ [Accessed 15 Jun 2020]. 
3 Blanchet K, Abbara A M, Fouad F. The effects of conflict on Syria's health system and human resources for health. World Health Popul 2016;16:87-95

4 Safeguarding Health in Conflict Coalition (SHCC). No Respite: violence against health care in conflict, 2021.

5 Druce P, Bogatyreva E, Siem FF, et al. Approaches to protect and maintain health care services in armed conflict - meeting SDGs 3 and 16. Confl Health 2019;13:2.

6 Friedrich MJ. Human rights report details violence against health care workers in Bahrain. JAMA 2011;306:475-6.

7 Fouad FM, Sparrow A, Tarakji A, et al. Health workers and the weaponisation of health care in Syria: a preliminary inquiry for the Lancet-American University of Beirut Commission on Syria. Lancet 2017;390:2516-26.

8 Physicians for Human Rights. A physician's ethical responsibility to provide care during time of war is identical to that during time of peace, 2020. Available: https://phr.org/issues/health-under-attack/ medical-neutrality/ [Accessed 26 May 2020].

9 Amnesty International. Health crisis: Syrian government targets the wounded and health workers. London, 2011.

10 Human Rights Council. Human rights situations that require the Council's attention: Assault on medical care in Syria, 2013.

11 ICRC. Protocol I (51) Protection of the civilian population. In: Protocol Additional to the Geneva Conventions of 12 August 1949, and relating to the Protection of Victims of International Armed Conflicts (Protocol I), Entry into force 7 December 1979, 1977.

12 Frontières MS. MSF-Analysis. treating Terrorists, 2015. Available: https://msf-analysis.org/new-treating-terrorists/ [Accessed 23 May 2020].

13 Physicians for Human Rights. Medical personnel are targeted in Syria, 2020. Available: https://phr.org/our-work/resources/medicalpersonnel-are-targeted-in-syria/ [Accessed 9 Feb 2020].

14 Koteiche R, Murad S, Heisler M. My only crime was that I was a doctor physicians hum. rights, 2019. Available: https://phr.org/ourwork/resources/my-only-crime-was-that-i-was-a-doctor/\#phr_toc_0 [Accessed 24 Apr 2020].

15 The Safeguarding Health in Conflict Coalition. Health workers at risk: violence against health care, 2020. Available: https:// www.safeguardinghealth.org/sites/shcc/files/SHCC2020final.pdf [Accessed 10 Jun 2020].

16 Kallström A, Häkkinen M, Al-Abdulla O, et al. Caught in crossfire: health care workers' experiences of violence in Syria. Med Confl Surviv 2021;37:34-54.

17 Fardousi N, Douedari Y, Howard N. Healthcare under siege: a qualitative study of health-worker responses to targeting and besiegement in Syria. BMJ Open 2019;9:e029651.

18 United Nations Office for the Coordination of Humanitarian Affairs. Syria anniversary press relase, 2020. Available: https://reliefweb.int/ sites/reliefweb.int/files/resources/USG Lowcock Syria Anniversary PR_ 06032020.pdf

19 Abbara A, Orcutt M, Gabbar O. Syria's lost generation of doctors. BMJ 2015;350:h3479.
20 Natasha H, Hosain M, Ho L. Effects of conflict on health. In: Conflict and health. Berkshire: Open University Press. McGraw Hill Education, 2012: 25-31.

21 Lafta R, Al-Ani W, Dhiaa S, et al. Perceptions, experiences and expectations of Iraqi medical students. BMC Med Educ 2018;18:53.

22 Bou-Karroum L, Daou KN, Nomier M, et al. Health Care Workers in the setting of the "Arab Spring": a scoping review for the LancetAUB Commission on Syria. J Glob Health 2019;9:010402.

23 Kronfol NM, Sibai AM, Rafeh N. The impact of civil disturbances on the migration of physicians: the case of Lebanon. Med Care 1992;30:208-15.

24 Burnham GM, Lafta R, Doocy S. Doctors leaving 12 tertiary hospitals in Iraq, 2004-2007. Soc Sci Med 2009;69:172-7.

25 Doocy S, Malik S, Burnham G. Experiences of Iraqi doctors in Jordan during conflict and factors associated with migration. Am J Disaster Med 2010;5:41-7.

26 Al-Khalisi N. The Iraqi medical brain drain: a cross-sectional study. Int J Health Serv 2013;43:363-78.

27 Elamein M, Bower H, Valderrama C, et al. Attacks against health care in Syria, 2015-16: results from a real-time reporting tool. Lancet 2017;390:2278-86.

28 Ri S, Blair AH, Kim CJ, et al. Attacks on healthcare facilities as an indicator of violence against civilians in Syria: an exploratory analysis of open-source data. PLoS One 2019;14:e0217905

29 Wong CH, Chen CY-T. Ambulances under siege in Syria. BMJ Glob Health 2018;3:e001003.

30 Footer KHA, Clouse E, Rayes D, et al. Qualitative accounts from Syrian health professionals regarding violations of the right to health, including the use of chemical weapons, in opposition-held Syria. BMJ Open 2018;8:e021096.

31 International Labour Office. International standard classification of occupations structure, group definitions and correspondence tables. ISCO-08, 2012. Available: https://www.ilo.org/wcmsp5/groups/ public/-dgreports/-dcomm/-publ/documents/publication/wcms_ 172572.pdf

32 Kaplan CD, Korf D, Sterk C. Temporal and social contexts of heroin-using populations. An illustration of the Snowball sampling technique. J Nerv Ment Dis 1987;175:566-74.

33 DeJonckheere M, Vaughn LM. Semistructured interviewing in primary care research: a balance of relationship and rigour. Fam Med Community Health 2019;7:e000057.

34 World Health Organization. World report on violence and health: summary. Geneva, 2002.

35 World Health Organization. Attacks on health care, 2019. Available: https://www.who.int/news-room/q-a-detail/attacks-on-health-care [Accessed 25 May 2020].

36 Tammi I-M. Politicians, pathogens, and other threats to aid workers: a material semiotic analysis of violence against health care in the Syrian conflict. Crit Stud Secur 2021:1-13.

37 Hamid A, Scior K, Williams ACdeC. Qualitative accounts from Syrian mental health professionals: shared realities in the context of conflict and forced displacement. BMJ Open 2020;10:e034291. 